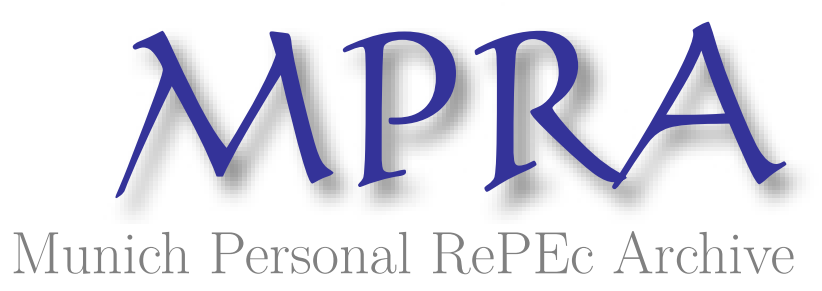

\title{
Three (Marginal?) Questions Regarding Convergence
}

Goerlich, Francisco José and Mas, Matilde

Instituto Valenciano de Investigaciones Económicas, Universitat de València

2004

Online at https://mpra.ub.uni-muenchen.de/15876/

MPRA Paper No. 15876, posted 25 Jun 2009 00:22 UTC 


\title{
THREE (MARGINAL?) QUESTIONS REGARDING CONVERGENCE
}

\author{
Francisco J. Goerlich
}

Matilde Mas

Universitat de València and Ivie 
Graduate and Doctor in Economics from the University of València. M.Sc. in Economics from the London School of Economics \& Political Science (University of London). He is currently Lecturer at the Department of Economic Analysis of the Universitat de València. His research fields are Macroeconomics and Applied Econometrics. Co-author of the book "Capitalización y Crecimiento en España y sus Regiones 1955-1995", (Fundación BBV, 1996) and "La Evolución Económica de las Provincias Españolas, 1995-1998 (2 volumes, Fundación BBVA, 2001). Has published his work in specialized journals such as Applied Economics, Economics Letters, Empirical Economics, Investigaciones Económicas, Moneda y Crédito, Revista Española de Economía and Revista de Economía Aplicada among others. Has participated in various national and international congresses. He is currently associate researcher of the DGCICYT project "Nuevos tipos de capital, crecimiento y calidad de vida: instrumentos de medida y aplicaciones" (SEC2002-03375).

Universitat de Valéncia. Departamento de Análisis Económico, Edificio departamental oriental. Avda. de los Naranjos, s/n; 46022 Valencia. Tel: 34.96.382.82.46 / Fax: 34.96.382.82.49 / Francisco.J.Goerlich@uv.es

Instituto Valenciano de Investigaciones Económicas (Ivie). c/ Guardia Civil, 22, Esc. 2, 1º, 46020 Valencia. Tel: 34.96.393.08.16 / Fax: 34.96.393.08.56

\section{Matilde Mas}

Graduate and Doctor in Economics from the Universitat de València. Lecturer in Economic Analysis at the same University, her specialized fields being Growth Economics, Analysis of Technological Change and of Public Capital, especially Infrastructures, Regional Economics and Housing Market. She is coauthor of the following books: Economía Española 1960-1980: Crecimiento y Cambio Estructural (Blume, 1982), Capital Humano, Series Históricas 1964-1992 (Fundació Bancaixa, 1995), El "Stock" de Capital en España y sus Comunidades Autónomas, 4 volumes, 4 editions (Fundación BBV), Capitalización y Crecimiento en España y sus Regiones, 1955-1995 (Fundación BBV, 1996), La VIvienda y el Sector de la Construcción en España (Fundación CAM, 2000) and La Evolución Económica de las Provincias Españolas, 1995-1998 (2 volumes, Fundación BBVA, 2001). Has published more than thirty articles in specialist journals such as Investigaciones Económicas, Moneda y Crédito, Papeles de Economía Española, Regional Studies, Review of Income and Wealth, Revista de Economía Aplicada, among others. She has participated in more than sixty national and foreign congresses and has given lectures as guest speaker in Spanish and foreign institutions. From October 2002 to January 2003 she has been Consultant at the OECD with the financial support of the Promotion and Mobility Program of Spanish Ministry of Education, Culture and Sports (PR2002-0287). She is associate researcher of the National Research Plan project "Nuevos tipos de capital, crecimiento y calidad de vida: instrumentos de medida y aplicaciones" (SEC2002-03375).

Universitat de Valéncia. Departamento de Análisis Económico, Edificio departamental oriental. Avda. de los Naranjos, s/n; 46022 Valencia. Tel: 34.96.382.82.46 / Fax: 34.96.382.82.49 / Matilde.Mas@uv.es

Instituto Valenciano de Investigaciones Económicas (Ivie). c/ Guardia Civil, 22, Esc. 2, $1^{\circ}, 46020$

Valencia. Tel: 34.96.393.08.16 / Fax: 34.96.393.08.56 


\title{
THREE (MARGINAL?) QUESTIONS REGARDING CONVERGENCE ${ }^{[1]}$
}

\begin{abstract}
This paper focuses on three (marginal?) questions surrounding the analysis of economic convergence and uses Spanish provinces as a means of illustration. The three questions in hand are the following: $(i)$ given that the geographical units of analysis are usually quite different in economic size, is the weighting of economic units relevant in convergence analysis? (ii) the average per capita income of a given region, or country, is the first moment in the distribution of income, but what about the second moment, inequality? Have we converged in inequality? and (iii) an aggregate welfare index must take into account, at least, the evolution of the first two moments of the distribution of income, and so does the adjustment for inequality make important differences in the evolution of average per capita income? The answer to the first two questions is yes, but to the third it is clearly no.
\end{abstract}

JEL: D31, R11

Keywords: Convergence, income distribution, inequality indices and regional analysis. 


\section{Three specific questions}

The aim of this paper is to analyse the available empirical evidence regarding three particular aspects of economic convergence, using as a means of illustration the Spanish provinces. Despite their intrinsic value, the three questions contemplated in this paper have received very little attention in the literature on growth and convergence. The emphasis of this paper is most decidedly empirical.

The convergence process in Spain, at a regional level, has been widely studied ${ }^{[2]}$. Nevertheless, the attention has almost exclusively been focused, from a macroeconomic point of view, on two key variables: per capita income and labour productivity. These variables are indistinguishable in a growth model with full capacity utilisation, although from an empirical viewpoint their behaviour may be notably different in both the short and the long run (Paci, 1997 and Goerlich and Mas, 1998). This paper focuses on per capita income ${ }^{[3]}$ and on two additional variables related to this: inequality and welfare (defined below). When we refer to inequality, we are explicitly referring to the inequality in the personal distribution of income within a given region, and not to the inequality between the average per capita incomes of the different regions. While the process of convergence of per capita income at the regional level in Spain is well understood, the convergence of inequality and welfare, or the lack of, and how these are related to the average provincial level of per capita income is practically unknown. In addition, we shall consider a methodological question with practical implications.

In order to analyse the evolution of inequality in the distribution of income, we have used the database which we had previously constructed from the Encuestas de Presupuestos Familiares (EPF's-Family Budget Surveys) of the INE (National Institute of Statistics) ${ }^{[4]}$ (Goerlich and Mas, 2001b). These surveys were carried out during the 
periods $1973 / 74,1980 / 81$ and 1990/91, which limits the period of study of the main part of this paper. Using this database, the Gini index has been selected as a measure of inequality ${ }^{[5]}$. The welfare variable has been constructed from the average per capita income and inequality.

However, before moving on to analyse the behaviour of these two variables, it is worth while focussing our attention on a question which seems to have gone, until recently (Sala-i-Martín, 2002), almost completely unnoticed in the literature on economic growth and convergence in either the regional or the international context. The Spanish provinces, much like other regions or countries, differ widely in economic size, given that this is defined in terms of population, surface area and the capacity to generate income (Goerlich and Mas, 2001a). Yet, the statistical instrument used in convergence analysis considers each province, region or country to be one single unit of analysis irrespective of its size and of the level of disaggregation used in the study. This would tend to imply that the results of the analysis might be different if the regionalisation of the country, or the frontiers at an international level, were drawn up differently (Jones, 1997) and suggests taking the economic size of each province into consideration, which in statistical terms would require the use of weighted statistics as opposed to simple or non-weighted ones.

As a consequence of this, the three specific questions being asked in this study are:

$\checkmark$ Does the weighting of regions or countries according to their economic size affect convergence analysis?

$\checkmark$ Per capita income is the first moment in the distribution of income. Inequality, or dispersion, in the distribution is the second moment and its evolution is equally 
important. Has inequality converged at the same time as the average levels of per capita income at the provincial level have?

$\checkmark$ The evolution of per capita income is commonly linked to the evolution of welfare in a society, a rather slippery concept. However, when income is unequally distributed, the average level of income per capita may be a very poor approximation of welfare. A minimum requirement for the correct measure of this concept would thus consist of taking the first two moments of the distribution into consideration. This notion suggests that per capita income and welfare may not necessarily follow the same tendency. Has welfare shown the same pattern of convergence as per capita income?.

In anticipation of the conclusions, the answer to the first two questions is yes, while the answer to the last question is clearly no.

\section{Does weighting matter? A digression with examples}

That the Spanish provinces differ in terms of their economic size is somewhat evident. For example, in 1999 Madrid represented $12.75 \%$ of the population and generated $16.82 \%$ of the national GVA, it being in both aspects the top Spanish province. At the other extreme, Soria, in the same year, was home to a mere $0.23 \%$ of the population and generated the same percentage of the national GVA. Should such diverse economic sizes be taken into consideration in convergence analysis? In our opinion, the answer is most definitely yes. 
A simple example should help to clarify this idea. Consider the cross-section distribution of per capita incomes of two moments in time, $t$ and $t+1$, for three different regions. Let $Y_{i}$ be the income and $N_{i}$ the population of region $i$, the per capita income is given as $x_{i}=\frac{Y_{i}}{N_{i}}$, and the size of the population, $N$, is constant and equal to 100 individuals who are unequally spread among the regions, $p_{i}=\frac{N_{i}}{N}$ being the proportion of the population of each region. This distribution can be seen in Table I.

Notice that, given that $x_{i}$ is the same for each region, in both $t$ and $t+1$, the simple statistics do not vary, the distribution of $x_{i}$ in terms of regions remains constant, the average is equal to 2 and the variance is equal to $2 / 3$. Inequality, however, in the sense that it has traditionally been understood in microeconomic literature, that is, the dispersion in the distribution of $x_{i}$ in terms of individuals, has increased, since a large proportion of the population has moved from the centre, region $\mathrm{B}$, to the extremes of the distribution: specifically, $15 \%$ have shifted downwards to the lower extreme, region $\mathrm{A}$, and another $15 \%$ have shifted upwards to the upper extreme, region $\mathrm{C}$. This situation is reflected in the inequality indices and also in the calculation of the statistics weighted by population shares. Thus, although the weighted average in $t$ and in $t+1$ remains equal to $2^{[6]}$, the weighted variance in $t$ is 0.5 while the weighted variance in $t+1$ is 0.8 , that is, there has been an increase in the dispersion. Consequently, the distribution of $x_{i}$ in terms of individuals shows an increase in inequality. Of course, none of this provides information about the distribution of personal income within each region.

The key question is: in terms of convergence, what conclusions may be drawn from this? Has a process of divergence occurred or has the distribution simply 
replicated itself? The macroeconomic literature on convergence, using simple statistics, would conclude that neither convergence nor divergence had taken place. In fact, if the regions are considered to be the unit of analysis, then what is of interest is the nonweighted distribution of $x_{i}$ and, as such, neither convergence nor divergence would be obtained, but simply a replica of the distribution. In statistical terms, if a random sample of regions is taken as reference, then weighting is not important.

If we accept that the per capita incomes being analysed have different population sizes behind them and we are interested in people's standard of living, then the correct unit is a "person" rather than a country or region. In statistical terms, if the reference population is the individual, then more weight should be given to the more densely populated regions. Not doing this, distorts the distribution characteristics being studied. This perspective leads us to conclude that, in the previous example, a process of divergence has in fact taken place.

The arguments just presented suggest that the question this epigraph opened with, that is, if the behaviour of per capita income should be analysed in terms of geographical areas or in terms of individuals, is not an easy one to answer. For this reason, it seems more sensible to set the question in a more practical context. For example, is it indifferent that countries such as Spain or France converge at the same average European level of income per capita as Luxemburg? It would appear not. Not only from the individual point of view is convergence greater if large regions converge than if small regions do so, irrespective of the nature of the income distribution within each region, but also that other relevant questions, such as the transference processes from rich regions to poor ones, depend substantially on the population size behind any given average income per capita. It would not be difficult to formulate examples whereby a result of economic divergence, obtained using simple statistics, is seen to be 
due to the systematic distancing from the average of one or two countries of insignificant size, such as Luxemburg; while adequate consideration of their relative sizes within the aggregate could provide the opposite result of economic convergence. Consequently, do simple and weighted statistics provide different interpretations of the same economic phenomenon? What does the data in our case tell us?

Graph 1 shows the evolution over time of two dispersion statistics, the coefficient of variation and the standard deviation of logs of the average income per capita for the Spanish provinces, in both the simple version and that weighted according to the population shares. Curiously, large differences are not observed despite the different population structures of the provinces. Thus, if we use aggregate dispersion measures we are only able to detect small differences between the simple and weighted statistics and, moreover, the general tendency of $\sigma$-convergence shown by both types of statistics is almost identical.

However, if we follow the advice of Quah (1993, 1996a y 1996b) and examine the external form of the distribution of the average provincial levels of per capita income, in this case, the weighted statistics do generate notable differences. Graph 2 shows the estimated density functions, simple and weighted ${ }^{[7]}$, of the income per capita normalised by the national value, $\frac{x_{i}}{\mu}$ being $\mu=\sum_{i=1}^{n} p_{i} x_{i}$, for the initial and final years of the sample, although the same pattern is observed for any other year. This graph clearly shows how the simple and weighted densities differ. For the Spanish provinces, a bi-modal structure can be clearly observed in the case of the weighted densities as a consequence of the fact that two of the provinces situated in the upper extreme of the 
distribution, Madrid and Barcelona, are densely populated. These two provinces together make up more than $20 \%$ of the total population of Spain, and as a result greater weight should be placed on the right hand side of the distribution. For this reason, the weighted densities display a twin-peak structure, very different form to the one outlined by the simple densities ${ }^{[8]}$.

The conclusion reached, therefore, is that weighting is important and, consequently, affects our perception of economic convergence. Nevertheless, it is necessary to go beyond the usual dispersion statistics, the coefficient of variation and the standard deviation of logs, given that these do not seem to be sufficiently sensitive to very different economic sizes.

\section{What happens to inequality in the distribution of income? Is there convergence in inequality?}

The average provincial level of per capita income is only the first moment in the distribution of income. Other moments, especially the second one, that is, the dispersion or inequality in the distribution, are also important. In fact, once augmented with idiosyncratic shocks, the neo-classical growth model implies convergence in distribution: countries or regions with the same fundamentals should tend towards the same invariant distribution of wealth and income. Hence not only average levels, but also dispersion, must converge. So the question is, are Spanish provinces converging to the same level of inequality? That is, is the distribution of income converging in dispersion in addition to converging in the mean level of per capita income? This 
question has almost entirely been ignored in the literature on economic growth, with the exception of a number of recent studies attempting to examine the relationship between growth and inequality ${ }^{[9]}$, and this is fundamentally due to the inexistence of a database on inequality measures comparable to that of Summers and Heston (1991). However, the recent appearance of an international database on inequality indices (Deininger and Squire, 1996) has meant that this question has finally begun to be examined (Bénabou, 1996).

In reference to the Spanish provinces, this topic has been studied in Goerlich and Mas (2002). Centred on the period 1973-1991 and the Gini index for total spending, we summarize the main characteristics of inequality at a provincial level, paying special attention to convergence.

Firstly, there was a reduction in inequality at a national level between 1973 and 1991: the average annual variation rate is negative for Spain as a whole and also for the majority of the provinces.

Secondly, the cross-section dispersion in Gini indices is decreasing through time, providing evidence of $\sigma$-convergence. Moreover, the reduction of interprovincial inequality was more intense in the second part of the period than in the first.

Thirdly, the dispersion of the Gini index is notably higher in the cross-section than in the time dimension. This result indicates that inequality is relatively stable within each province but varies considerably between provinces. The stability of inequality over time is probably a more sensible description of the data than the Kuznets hypothesis, which defends an inverted-U relationship between inequality and average income levels. 
Fourthly, the interprovincial mobility in inequality indexes is relatively high. This mobility is being measured by the correlation between the initial and final positions, either in levels or rankings. This correlation is always lower than for per capita income levels. Also, a stable and negative correlation with the average per capita income is observed. This means that wealth and inequality are geographically opposite.

Finally, as in the case of per capita income, there is strong evidence of $\beta$ convergence in inequality. For the period 1973-1991, a cross-section equation of absolute convergence of income per capita provided the following results

$$
\frac{1}{18}\left(\log y_{i, 91}-\log y_{i, 73}\right)=\hat{\alpha}-0.0149 \log y_{i, 73}+\hat{u}_{i, 91} \quad \mathrm{R}^{2}=0.3832
$$

$$
\chi_{\text {Normality }}^{2}(2)=0.52(0.7697) \quad \chi_{\text {Heteroskedasticity }}^{2}(2)=1.61(0.4478)
$$

where $\chi_{\text {Normality }}^{2}$ is the Jarque and Bera (1980) normality test and $\chi_{\text {Heteroskedasticity }}^{2}$ is the White (1980) test for heteroskedasticity with $p$-values in brackets. Hence, the initial value is negative and strongly significant in a convergence equation, which provides evidence of $\beta$-convergence at an annual rate of $1.73 \%^{[10]}$. For the Gini indices, the convergence equation provided the following results

$$
\begin{gathered}
\frac{1}{18}\left(\log g_{i, 91}-\log g_{i, 73}\right)=\hat{\alpha}-0.0407 \log g_{i, 73}+\hat{u}_{i, 91} \quad \mathrm{R}^{2}=0.4293 \\
(0.0068) \\
\chi_{\text {Normality }}^{2}(2)=0.60(0.7411) \quad \chi_{\text {Heteroskedasticity }}^{2}(2)=4.02(0.1338)
\end{gathered}
$$

where $g_{i}$ represents the Gini index and the annual speed of convergence is $7.34 \%$, very much superior to that of the per capita income. 


\section{Per capita income versus welfare: do adjustments made for inequality generate notable differences?}

The results concerning growth and convergence in per capita income or productivity are normally transferred, either implicitly or explicitly, in terms of gains or losses in welfare for the society as a whole. However, it is well known that when there are differences in the distribution of income, the average income per capita of a region is a poor approximation of the aggregate welfare of this economic unit.

It is generally accepted that welfare in a society is positively related to the average level of income and negatively related to the inequality existing in the distribution of it. An indicator of aggregate welfare, therefore, should take this trade-off into account. The key question is, then, if the evolution of inequality can invert, or at least substantially alter, the results obtained regarding convergence and growth in per capita income. As we shall see below, the answer to this question is clearly no.

We can define a welfare index from the average income per capita, $x_{i}$, and an inequality index which varies between zero and one, $g_{i}$, as (Sen, 1974)

$$
\omega_{i}=x_{i}\left(1-g_{i}\right)
$$

and analyse the convergence of this variable, where $g_{i}$ represents again the Gini index.

If dispersion statistics for welfare are calculated, such as the variation coefficient or the standard log deviation, and are then compared to the statistics corresponding to the income per capita only small nonsignificant differences are found, in both simple and weighted terms ${ }^{[11]}$, as shown in Table II. 
In addition, if we examine the external form of the distribution of the welfare indices at a provincial level, we find that there are no great differences (Graph 3). The weighting, however, is relevant, but the adjustment for inequality does not seem to be of any great consequence.

Finally, a convergence equation in terms of welfare yielded the following result,

$$
\frac{1}{18}\left(\log \omega_{i, 91}-\log \omega_{i, 73}\right)=\hat{\alpha}-0.0152 \log \omega_{i, 73}+\hat{u}_{i, 91} \quad \mathrm{R}^{2}=0.3818
$$

$$
\chi_{\text {Normality }}^{2}(2)=0.39(0.8227) \quad \chi_{\text {Heteroskedasticity }}^{2}(2)=1.35(0.5103)
$$

which is almost identical to that obtained for the per capita income. The annual speed of convergence implicit in this equation is $1.78 \%$, only slightly greater, as expected, than that for the per capita income, given the behaviour of the Gini indices.

Consequently, we are confident that the convergence results obtained for the income per capita can be transformed in a direct way in terms of social welfare, at least when the Sen's index is used. In the case of the Spanish provinces, this is due to the small variability in the inequality indices in relation to the average provincial levels of per capita income ${ }^{[12]}$.

\section{Conclusions: Three specific answers.}

The three questions posed at the beginning of this paper can now be answered in a clear and concise way. 
$\checkmark$ (i) Does the weighting of regions or countries according to their economic size affect convergence analysis? Without doubt the answer is YES. It may not seem so if the statistical instrument is restricted to aggregate dispersion statistics, but most definitely there are substantial differences if the vision is widened to the total distribution. As a minimum requirement, studies surrounding this theme should examine both types of statistics, given that they reveal different yet complementary information.

$\checkmark$ (ii) Has inequality converged at the same time as the average levels of per capita income at the provincial level have? Once again the answer is YES. In terms of convergence, a qualitatively similar evolution has been detected.

(iii) Do adjustments made for inequality in the per capita income, used to measure welfare, generate substantial differences in both magnitudes from the point of view of convergence? Unlike the two previous questions the answer in this case is NO, at least if Sen's welfare index is used. Consequently, from the point of view of convergence, the affirmations regarding per capita income can be transferred directly to welfare. 


\section{References}

BBV (various years), Renta Nacional de España y su Distribución Provincial, Banco de Bilbao y Banco Bilbao-Vizcaya.

Bénabou, R. (1996), “Inequality and growth”, NBER Macroeconomics Annual, 11-73.

Cuadrado-Roura, J. R., García-Greciano, B. and Raymond, J. L. (1999), "Regional convergence in productivity and productive structure: The Spanish case", International Regional Science Review, 22, 1, (April), 35-53.

Deininger, K. and Squire, L. (1996), "Measuring income inequality: A new database", The World Bank Economic Review, 10, 565-591.

Gardeazabal, J. (1996), "Provincial income distribution dynamics: Spain 1967-1991", Investigaciones Económicas, 20, 263-269.

Goerlich, F. J. (2000), “Desigualdad, diversidad y convergencia: (más) instrumentos de medida -Estadística descriptiva-", Monograph. Instituto Valenciano de Investigaciones Económicas. (http://www.ivie.es).

Goerlich, F. J. (2003), "Weighted samples, kernel density estimators and convergence”, Empirical Economics, 28, 2, 335-351.

Goerlich, F. J. and Mas, M. (1998), "Medición de la desigualdad: variables, indicadores y resultados", Moneda y Crédito, 207, (Noviembre), 59-86.

Goerlich, F. J. and Mas, M. (2001a), La Evolución Económica de las Provincias Españolas 1955-1998. Volumen II. Desigualdad y Convergencia, Fundación BBVA. 
Goerlich, F. J. and Mas, M. (2001b), "Inequality in Spain, 1973-91: Contribution to a Regional Database", Review of Income and Wealth, 47, 3, (September), 361-378.

Goerlich, F. J. and Mas, M. (2002), "Intertemporal and interprovincial variations in income inequality: Spain 1973-1991”, Regional Studies, 39, 9, (December), 1005-1015.

INE (various years), Anuario Estadístico de España. Instituto Nacional de Estadística, Madrid.

Jarque, C. M. y Bera, A. K. (1980), "Efficient tests for normality, homocedasticity and serial independence of regresión residuals", Economics Letters, 6, 3, 255-259.

Jones, C. I. (1997), “On the evolution of the World income distribution", Journal of Economics Perspectives, 11, 3, (Summer), 19-36.

López-Bazo, E., Vaya, E., Mora, A. J. and Suriñach, J. (1996), "Regional economic dynamics and convergence in Spain and Europe”, European Regional Science Association, 36th European Congress, ETH Zurich, Switzerland, 26-30 August.

Mas, M., Maudos, J., Pérez, F. and Uriel, E. (1995), "Growth and convergence in the Spanish provinces", in Amstrong \& Vickerman (Eds.) Convergence and Divergence among European Regions. Chp.-13, Ed. Pion.

Paci, R. (1997), "More similar and less equal: Economic growth in the European regions", Weltwirtschaftliches Archiv, 133, 4, 609-634.

Persson, T. and Tabellini, G. (1994), "Is inequality harmful for growth", American Economic Review, 84, 3 (junio), 600-621. 
Quah, D. (1993), "Galton's fallacy and test of the convergence hypothesis", The Sandinavian Journal of Economics, 95, 4, (December), 427-443.

Quah, D. (1996a), “Twin peaks: Growth and convergence in models of distribution dynamics”, Economic Journal, 106, 437, (July), 1045-1055.

Quah, D. (1996b), "Regional convergence clusters across Europe", European Economic Review, 40, 3/5, (April), 951-958.

Sala-i-Martín, X. (2002), “15 years of new growth economics: What have we learnt?”, Discussion Paper \#0102-47, Discussion Paper Series, Department of Economics, Columbia University.

Sen, A. (1974), "Informational bases of alternative welfare approaches. Aggregation and income distribution", Journal of Public Economics, 3, 387-403.

Silverman, B. W. (1986), Density Estimation for Statistics and Data Analysis, Chapman \& Hall, Monographs on Statistics and Applied Probability $\mathrm{n}^{\circ}$ 26, London.

Summers, R. and Heston, A. (1991), “The Penn World Table (Mark 5): An expanded set on international comparisons, 1959-1988”, Quarterly Journal of Economics, $106,2,327-368$.

Tanzi, V. and Chu, K. (1998), (Eds.) Income Distribution and High-Quality Growth, MIT Press, Cambridge, Massachusetts.

White, H. (1980), “A heteroskedasticity-consistent covariance matrix estimator and a direct test for heteroskedasticity”, Econometrica, 48, 4, (May), 817-838. 


\section{NOTES}

${ }^{[1]}$ The authors would like to thank J.C. Robledo for his help in gathering the statistical information. This paper comes under the projects DGCYCIT, SEC2002-03375, and Conselleria de Innovación y Competitividad de la Generalitat Valenciana, CTIDIB/2002/209. Francisco J. Goerlich gratefully acknowledges the financial support of the Instituto Valenciano de Investigaciones Económicas (Ivie). Some of the ideas contained in this paper have previously appeared in Goerlich (2000) and Goerlich and Mas (2001a, 2002).

[2] See, amongst many others, Mas, Maudos, Pérez, and Uriel (1995), Gardeazabal (1996), López-Bazo, Vaya, Mora and Suriñach (1996), and Cuadrado-Roura, García-Greciano and Raymond (1999).

${ }^{[3]}$ Defined as Gross Value Added (GVA) over Population. The data for provincial GVA, 1955-1999 base 1986, have been provided by the Fundación BBV (various years) and for Population by Anuario Estadístico of the INE (various years). The results of this paper are robust to the use of other measures of income, such as Gross National Product or Disposable Family Income.

${ }^{[4]}$ Available at http://www.ivie.es. National data can also be found in the WIDER database of the United Nations (http://wider.unu.edu/wiid/wiid.htm).

[5] The results, however, are robust to the use of other indices of inequality available from the same database.

[6] That the simple and weighted averages in $t$ and $t+1$ are always the same is derived from the fact that the simple as well as the weighted distribution is always symmetric in both periods. Obviously this is not a general characteristic, simply that the example has been simplified to the extreme.

[7] These densities use a gaussian kernel, an optimal bandwidth and a reflection method to take into account the non-negativity in the data (Silverman, 1986). Weighted densities substitute a simple sum for a weighted sum in the calculations.

${ }^{[8]}$ It could be suggested that the importance of the weighted densities is only relevant for our data set, however, something similar occurs with other databases widely used in convergence analysis at an international level such as the Penn World Table (Summers and Heston, 1991). In this latter case, even the aggregate dispersion statistics display different behaviours when comparing simple and weighted ones. Of course, the density functions display even greater differences (see Goerlich, 2003 for details).

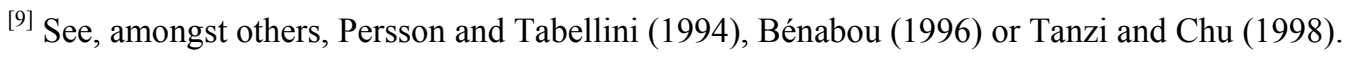

${ }^{[10]}$ The annual rate of convergence is calculated as

$$
-\frac{100}{18} \log (1+18 . \beta)
$$

where $\beta$ is the coefficient on the initial condition in the convergence equation.

${ }^{[11]}$ The weighted statistics for the welfare variable are weighted by population shares, just as was done for the income per capita. However, it is important to note that given that $\omega_{i}$ is a nonlinear function of $x_{i}$ and $g_{i}$ and that, furthermore, the aggregate Gini index is not a weighted average of the provincial Gini indices, aggregate welfare does not correspond exactly to the weighted average of the provincial welfare indices.

${ }^{[12]}$ Our experience tells us that this is also the case with other data sets such as the Penn World Table and the database of Deininger and Squire (1996), where inequality is much more variable between countries. In any case, here the differences in income per capita are also much greater than in inequality. For this reason, the evolution followed by the first of these variables is not substantially altered by the second. A possible explanation for this result is the presence of relatively slow rates of population mobility among geographical areas. 
TABLE I.

Two hypothetical distributions of per capita income.

\begin{tabular}{|c|c|c|c|c|}
\hline \multirow{2}{*}{ Region } & \multicolumn{2}{|c|}{$t$} & \multicolumn{2}{c|}{$t+1$} \\
\cline { 2 - 5 } & $x_{i}$ & $p_{i}$ & $x_{i}$ & $p_{i}$ \\
\hline A & 1 & 0.25 & 1 & 0.40 \\
B & 2 & 0.50 & 2 & 0.20 \\
C & 3 & 0.25 & 3 & 0.40 \\
\hline
\end{tabular}

TABLE II.

Simple versus weighted statistics.

Welfare

\begin{tabular}{|c|c|c|c|c|}
\cline { 2 - 5 } \multicolumn{1}{c|}{} & \multicolumn{2}{c|}{ Variation Coefficient } & \multicolumn{2}{c|}{ Standard Deviation of Logarithms } \\
\cline { 2 - 5 } & Simple & Weighted & Simple & Weighted \\
\hline 1973 & 0.291 & 0.291 & 0.289 & 0.308 \\
1981 & 0.259 & 0.250 & 0.260 & 0.267 \\
1991 & 0.236 & 0.231 & 0.233 & 0.242 \\
\hline
\end{tabular}




\section{GRAPH 1.}

Simple versus weighted statistics

Income per capita

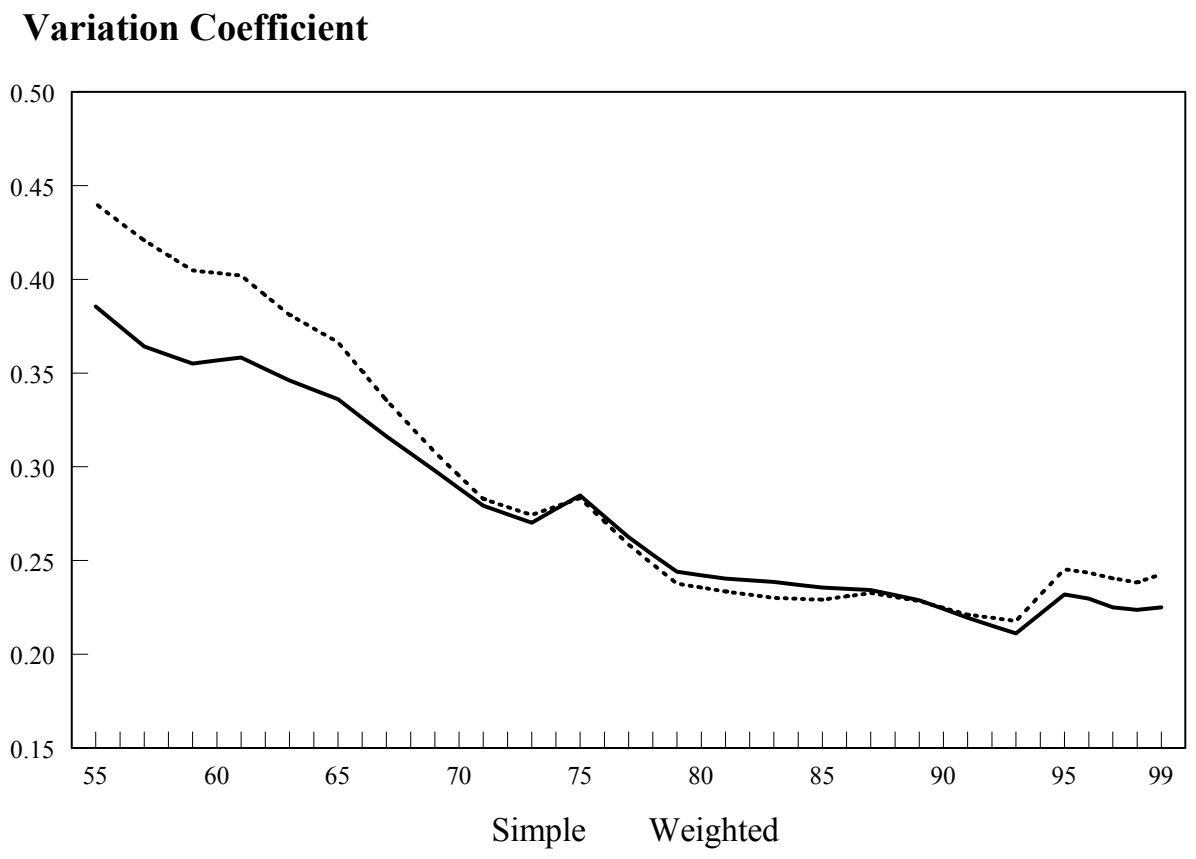

\section{Standard Deviation of Logarithms}

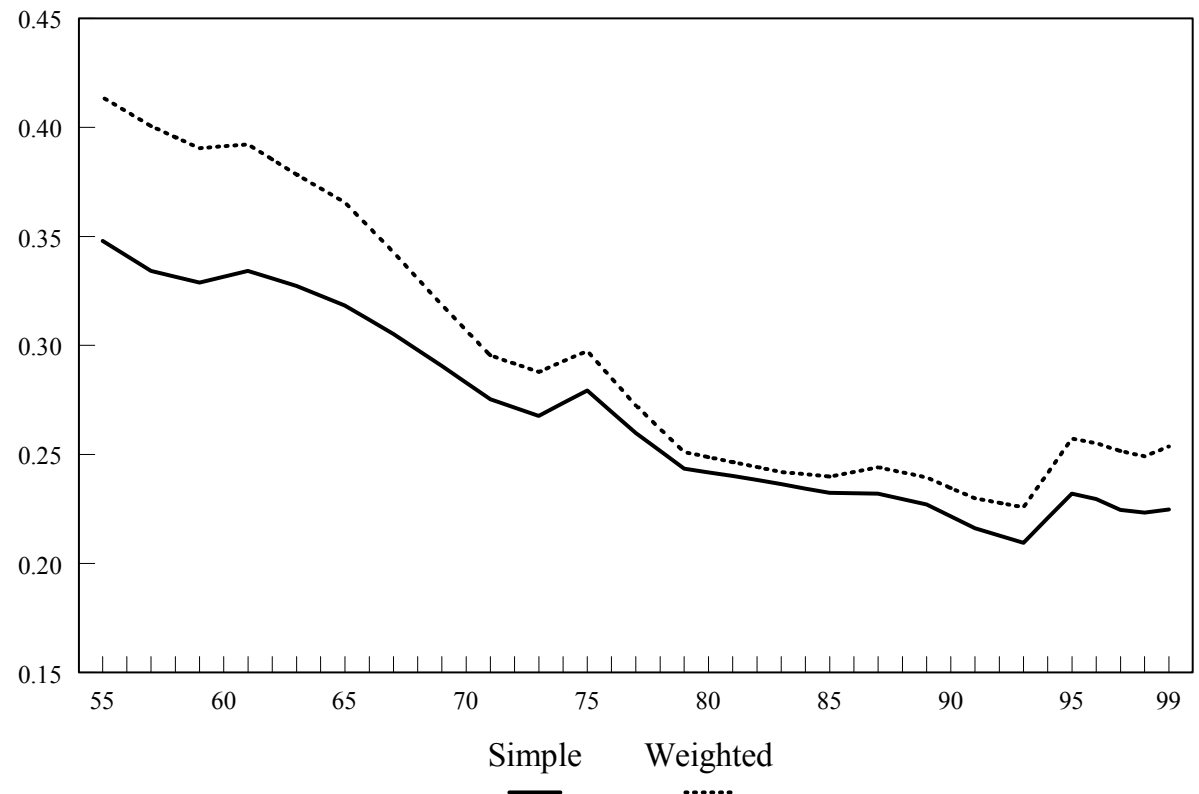


GRAPH 2.

Simple versus weighted statistics

Income per capita

\section{Density Functions. 1955}

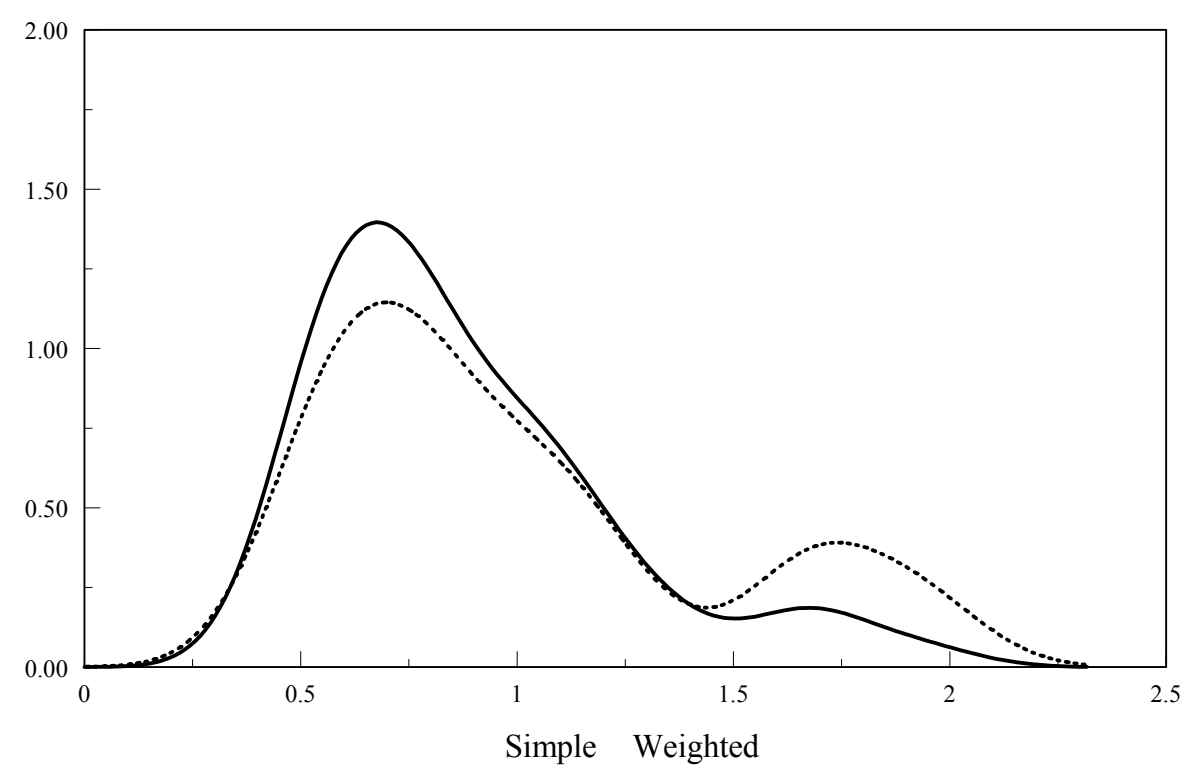

Density Functions. 1999

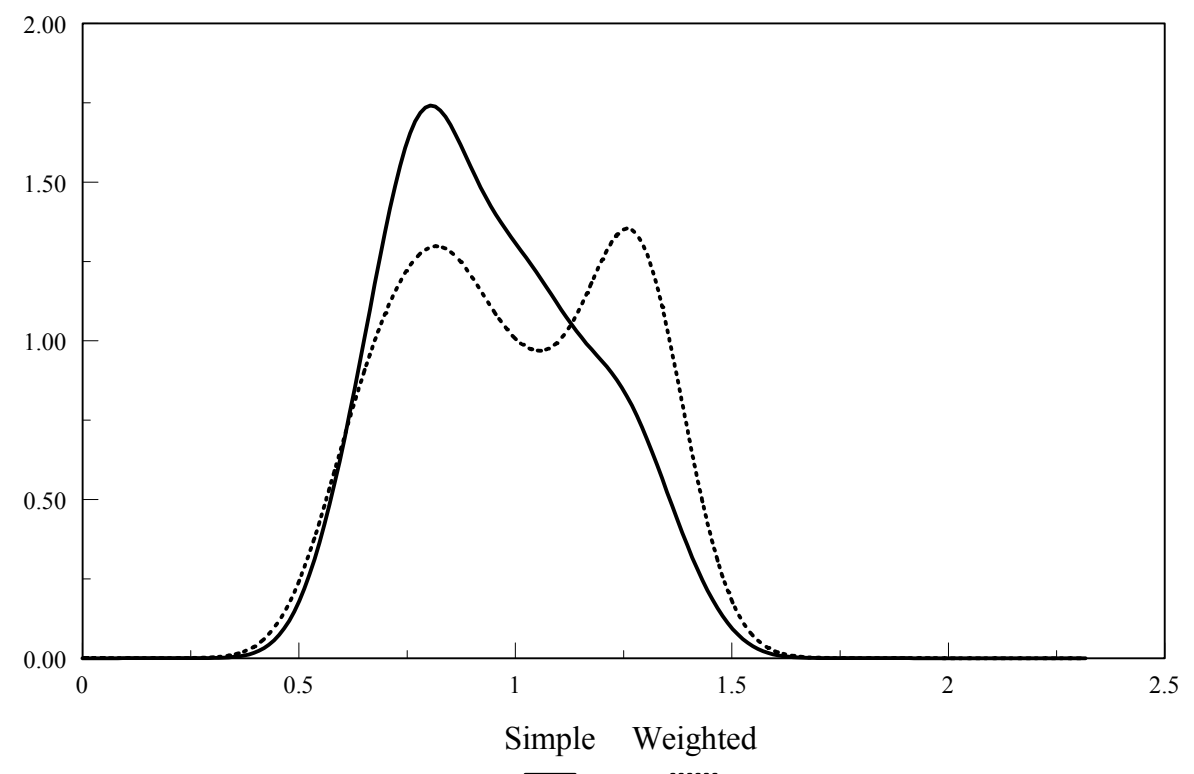


GRAPH 3.

Income per capita versus welfare

a) Density Functions. 1973
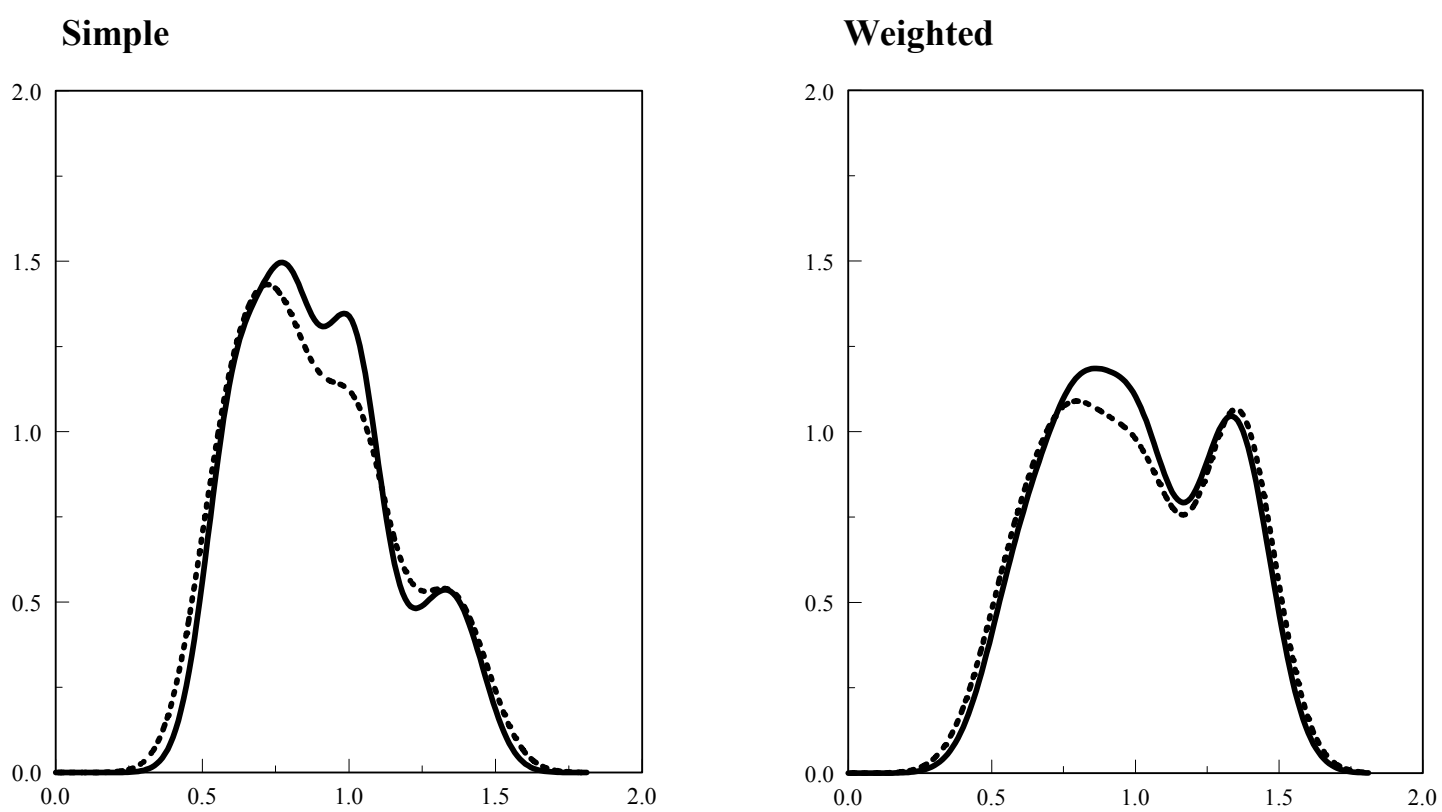

b) Density Functions. 1991
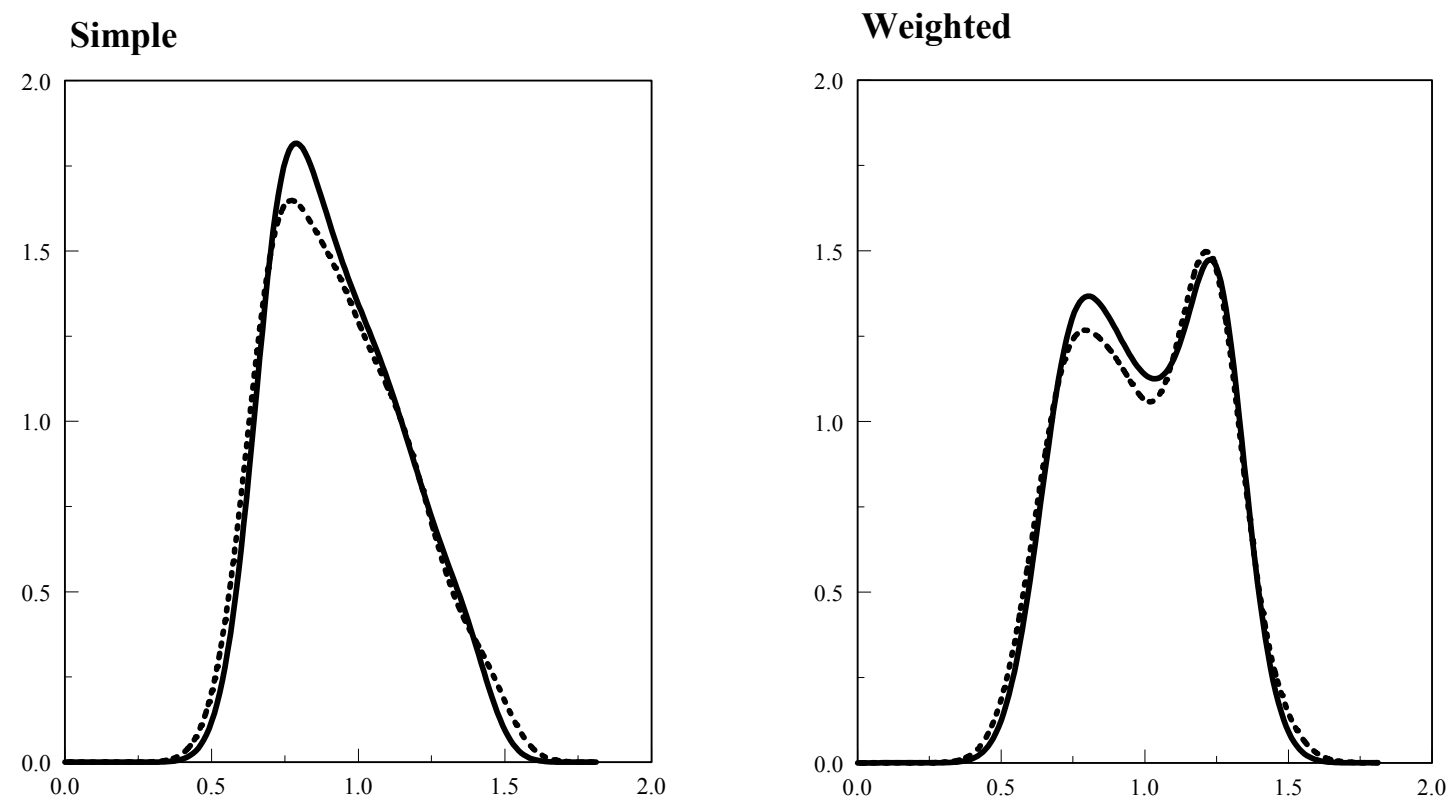

Income per capita

Welfare
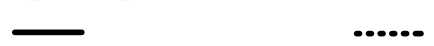